${ }^{I}$ Departamento de Sociologia e Programa de

Pós-Graduação em Sociologia e Antropologia, Universidade

Federal do Rio de Janeiro (PPGSA/UFRJ), Brasil

marcosilvasantana@gmail.com

IIInstituto de Estudos Sociais e Políticos da Universidade

do Estado do Rio de Janeiro (IESP/UERJ), Brasil

igorperesjeronimo@gmail.com

Marco Aurélio Santana'

Igor Peres"

\title{
CAPITALISMO, CIDADE E POLÍTICA NA PERSPECTIVA DE DAVID HARVEY
}

\section{TRAÇANDO UM PERCURSO}

David Harvey é um dos autores inescapáveis do atual cenário intelectual internacional. Seja por sua longa e arguta produção acadêmica, seja por sua relação com os movimentos sociais, ou, ainda, por sua aguda leitura e desafiadores usos da obra de Karl Marx, Harvey se tornou um intelectual de forte presença no debate global. ${ }^{1}$ Ele tem sido um dos autores mais citados no âmbito das ciências humanas, também com forte presença nos eventos promovidos pelos movimentos sociais globais, bem como um dos intelectuais que tem contribuído para um aggiornamento da teoria marxista. Neste particular, junto a outros autores importantes, tem sido uma ponta de lança para uma revitalização dos estudos baseados na obra de Marx. Não é por acaso, portanto, que Alex Callinicos, em texto escrito há alguns anos sobre a contribuição do autor em tela para o desenvolvimento da tradição prático-teórica marxista, asseverou que "qualquer apreciação histórica do desenvolvimento da teoria marxista no final do século XX agraciaria David Harvey com um dos primeiros lugares" (Callinicos, 2006: 47).

Seu itinerário, contudo, no que diz respeito à temática organizadora de suas preocupações, que podemos definir sumariamente como o problema do desenvolvimento desigual do espaço, não é linear. Acompanhando suas investidas reflexivas desde os escritos iniciais nota-se seu trânsito tenso e construtivo pelas mais variadas tradições de pensamento que vão desde Rudolph Carnap e Karl Popper, passando por Henri Lefebvre até desembocar, não, é claro, necessariamente nesta ordem, em Karl Marx e Friedrich Engels, Vladimir Lenin, Rosa Luxemburgo e Giovanni Arrighi. ${ }^{2}$ Pode-se dizer a respeito que 
a epítome "friccionar blocos conceituais" (Harvey, 2005: 38) em proveito de soluções inventivas e teoricamente proveitosas tenha sido mesmo o projeto analítico orientador de sua trajetória.

Talvez a inflexão mais notável de nosso autor tenha se dado com relação ao que tachou, a posteriori, de geografia pré-crítica ou pré-radical, "escola" notadamente marcada por certo pathos empírico-excepcionalista, ${ }^{3}$ progressivamente preterido por Harvey em prol do desenvolvimento de um materialismo histórico-geográfico. Distanciamento avaliativo e/ou diálogo crítico qualificado este, representativo de um exercício de crítica imanente do autor em pelo menos dois sentidos. Por um lado, Harvey, como se sabe, é geógrafo e acompanhou o desenrolar das discussões que se referem diretamente ao campo da geografia desde dentro. Por outro, imanente, pois que sua crítica positiva à geografia parte de um questionamento interno de seus pressupostos e conteúdos para fazer transparecer em "terreno inimigo", digamos assim, suas debilidades. ${ }^{4}$

Neste texto, evitando a apreciação de seus primeiros trabalhos, já sumariados, por exemplo, em Barnes (2006) e Gregory (2006), apresentamos um dos roteiros possíveis de acesso ao pensamento do geógrafo inglês, de forma não exaustiva, buscando apreciar termos e/ou conceitos que contribuíram para moldar uma espécie de léxico harveyano, dentre os quais elegemos: rearranjo espacial (spatial fix), ${ }^{5}$ novo imperialismo (new imperialism) e acumulação mediante despossessão (accumulation by despossession). Como forma de enraizar tais ideias e formulações mais gerais, refletimos sobre sua contribuição relativa à cidade. Concluímos este roteiro com algumas notas acerca do que seria a teoria crítica desenvolvida pelo autor.

\section{O REARRANJO ESPACIAL}

A formulação da noção de rearranjos espaciais de Harvey é profundamente marcada pelos anos de trabalho que resultaram em The limits to capital (1982). O livro que o autor reputa como um dos mais difíceis de concluir de sua carreira "[tomando-o] boa parte de uma década" (Harvey, 2005: 25), é resultado de um estudo detalhado sobre 0 capital de Marx. A partir da exegese do texto marxiano, notadamente o escrutínio dos mecanismos de acumulação do modo de produção capitalista e de sua tendência a gerar crises, buscará assentar as bases para a confecção de suas contribuições mais inventivas, entendidas por Harvey como necessárias para preencher algumas lacunas da teoria marxista em particular e da teoria social como um todo (Harvey, 2005: 142).

Esta incursão sobre a obra de Marx, após a inflexão reflexiva preparada por seus dois primeiros trabalhos mais importantes Explanation in geogra- 
phy (1969) e Justiça social e a cidade (1980), concorrerá definitivamente para a armação de uma estrutura lógica que acompanhará o geógrafo inglês até suas preocupações mais recentes.

Neste sentido, a apropriação da obra do autor alemão não foi de todo exclusivamente explanatória. Conforme Harvey, Marx, por ter se preocupado em traçar um retrato detalhado do modus operandi do modo de produção capitalista, isto é, de seus mecanismos de vertebração internos com forte esteio na produção do tempo, não teria dado atenção, de forma mais sistemática e abrangente, ${ }^{6}$ ao aspecto espacial.

Nosso autor tributa este descuido a ao menos dois motivos: por um lado, estariam as dificuldades crônicas e, portanto, costumeiras relativas ao entendimento do espaço, notadamente devido às suas "propriedades mais complexas e específicas que o tempo", resultando em sua difícil "metrificação" (Harvey, 2005: 145). Por outro, Harvey menciona um motivo propriamente analítico relativo à fundamentação da teoria do valor utilizada por Marx (e, deve-se registrar, por alguns dos economistas clássicos) como sendo baseada, como é notório, no tempo de trabalho socialmente necessário para a produção de uma mercadoria.

A assertiva aqui não deve ser tomada literalmente ou, o que neste caso significa o mesmo, de maneira unilateral, apesar de Harvey o fazer amiúde em seus textos (ele mesmo o atesta autocriticamente em Harvey, 2005: 143). Marx não se preocupou exclusivamente com o aspecto temporal em suas formulações, o raciocínio simétrico inverso valendo para o geógrafo. Isto é, apesar de tomar como sua tarefa o desenvolvimento de um materialismo histórico-geográfico, que teria como objeto o desenvolvimento geográfico histórico desigual, Harvey tematizou de maneira proveitosa a questão das temporalidades, ou mais precisamente o que chama de temporal fix, assunto que abordaremos apenas lateralmente (para mais detalhes, ver Jessop, 2006).

A reflexão espacial é introduzida por Harvey de forma radicalmente articulada a sua concepção dos movimentos de acumulação do capital. O motivo é bastante simples: sendo as crises entendidas por Harvey como crises de sobreacumulação de força de trabalho (desemprego) e capital (na forma de mercadorias, capacidade produtiva e moeda), a produção do espaço serviria basicamente como depositório dinâmico para absorvê-los e rearranjá-los. Isto é, Harvey busca integrá-lo (o espaço) no arcabouço teórico acumulado para a compreensão dos mecanismos de postergação - a curto, médio e longo prazos - para as crises do capitalismo, subtraindo-lhe o status de categoria residual e atribuindo-lhe estatuto positivo e central para o entendimento da dinâmica capitalista.

Para pensá-lo, naquilo que é um exercício de crítica reconstrutiva, Harvey tira proveito dos trabalhos de autores como Hegel, Von Thünen e do próprio Marx (Harvey, 2004: 95-122), absorvendo seus achados e reconstruindo- 
- os a partir de suas debilidades. Lendo o Hegel da Filosofia do Direito, e tomando-o como o ponto de partida para boa parte de suas análises, notará que o filósofo encontrava-se diante de um dilema: deveria formular uma saída para as tensões postas no interior da sociedade civil que ele concebia como egoística, em contraposição à esfera familiar, dominada, Hegel supunha, pelo altruísmo. Para solucioná-lo, a sociedade civil seria forçada a buscar uma saída externa às suas contradições internas em outros países, impelindo-se para além de suas fronteiras, fundando colônias, por exemplo (ver Harvey, 2004: 105-106; 2005: 98-101, 194-195).

Quanto a Marx, a tentativa de compreensão e reconstrução da teoria do alemão por parte de Harvey teria se iniciado com uma inquietação: "Muitas vezes quis saber por que o primeiro volume de O capital, de Marx, termina com um capítulo sobre 'a teoria moderna da colonização'"7 (Harvey, 2005: 97). Apesar de Marx tratar, pelo menos em duas oportunidades mais substanciais, uma no fim do Livro I de O capital e outra posicionada no Livro III da mesma obra, primeiro da "colonização" e, em seguida, do "comércio exterior" como alternativa à tendência crônica do capitalismo a gerar crises, Harvey classifica a preocupação de Marx como assistemática, isto é, esparsa e pouco problematizada, sem deixar, entretanto, de delimitar suas diferenças relativamente às formulações de Hegel.

Ou seja, o que a lógica idealista deste último entendia como uma solução para a tensão montante entre egoísmo e o altruísmo, é enxergado por Marx como uma reposição da contradição em qualidade e modalidades renovadas. Emprestando centralidade à relação assimétrica constitutiva do modo de produção capitalista, Marx entende, segundo Harvey, a mudança para as colônias como reposicionamento das contradições entre as classes e a renovação espacial dos mecanismos de sua reprodução.

Apesar desta diferença, o geógrafo arremata, como de resto havia feito também com Hegel (Harvey, 2005: 100-101), classificando como insatisfatório o posicionamento de Marx. Segundo ele,

os marxistas, paradoxalmente, não encontram muita ajuda em Marx (certamente não em $O$ capital). Para Marx ainda que supremamente cônscio da unidade subjacente dos assuntos políticos e econômicos, assim como da dinâmica global do capitalismo, a excluída consideração específica a respeito do ajuste espacial nos fundamentos que integravam, na teoria, questões de comércio exterior, da expansão geográfica e outras mais, apenas complicou os fatos, sem necessariamente acrescentar algum dado novo. [...] Mas num mundo onde a "Pax Britannica" de Palmerston reinava segura, e posicionado como Marx estava, ou seja, no centro do capitalismo laisser-faire, com todas as suas lisonjas ideológicas, Marx tinha pouco estímulo para ir além, descrevendo o arranjo espacial como nada mais do que a projeção violenta das contradições do capitalismo sobre o palco mundial. A sua preocupação maior, e a contribuição de O capital, foi elucidar a natureza dialética interna do capitalismo (Harvey, 2005: 123. grifos nossos). 
De sua parte, alternativamente, em um artigo de preparação para suas formulações sobre os rearranjos, Harvey dizia tentar alicerçar o que chamou de "escalas intermediárias" alocadas entre a postulação mais abstrata dos mecanismos de reprodução do capital e sua configuração imperialística posterior, o que significaria a atenção mais detalhada às possíveis formas de combinação entre uma "teoria da localização e a análise dos investimentos fixos e imobilizados, e a criação obrigatória da paisagem geográfica para facilitar a acumulação através da produção e da circulação" (Harvey, 2005: 73).

A importância que Marx havia dispensado aos elementos como transporte e comunicação (capital fixo) para a "anulação do espaço pelo tempo", isto é, a diminuição do que Harvey chamou inventivamente de "tempo de giro necessário" (socially necessary turnover time) para a realização de uma mercadoria, estaria, de acordo com o geógrafo, correta, mas apenas parcialmente (Harvey, 2005: 138). Para tornar a formulação analiticamente mais abrangente e frutuosa, o espaço deveria passar de obstáculo a ambiente geográfico portador de dinâmicas complexas próprias, além de loci aglutinadores de ambiências com durações mais ou menos prolongadas no tempo.

O rearranjo espacial representaria basicamente a constante criação e (re) criação de novas "paisagens geográficas", capazes de absorver novos excedentes. A movimentação deste novo espaço se tornaria mais e mais complexa ao longo do tempo. Após a fixação de um novo espaço, Harvey chega mesmo a mencionar a tendência à formação de alianças regionais de classe, não obstante algum grau de instabilidade, podendo-se atingir posteriormente estágios do que ele nomeia, tomando um conceito emprestado de Philippe Aydalot, "coerência estruturada", ou seja, certa calcificação de uma determinada configuração socioespacial (Harvey, 2005: 151-153).

Cabe notar, como o faz Jessop (2006: 147), que o termo rearranjo (fix), em Harvey, comporta duas acepções. Por um lado, o termo guardaria um sentido mais literal, como algo que realmente fixa-se fisicamente num espaço determinado. De outro, indicaria, numa acepção mais metafórica, a ideia de improvisos, à maneira de concertações ad hoc.

Além das expressões destes rearranjos que, supõe-se, na medida em que Harvey não o esclarece, seriam internas, o autor chama a atenção para algumas das principais modalidades de exteriorização espacial: a) desenvolvimento de mercados alhures no interior do mundo capitalista para suprir problemas de subconsumo; b) comércio com espaços não-capitalistas para expandir mercados; c) exportação de mais-valia para estabelecer novas facilidades produtivas; d) expansão do proletariado a partir da separação de camponeses, artesãos, trabalhadores por conta própria e mesmo alguns capitalistas do controle de seus meios de produção (ver Jessop, 2006: 149).

Da forma como nos aponta Harvey, estas estruturas durariam até que outras crises se formassem e houvesse, portanto, a necessidade de rear- 
ranjos renovados, com o espaço criado sendo transformado de solução em novo problema a ser ultrapassado. Na medida em que Harvey compreende estas saídas como necessariamente provisórias, a longo prazo, a sucessão de rearranjos espaciais tenderia a se espraiar para o âmbito internacional, agudizando o caráter geopolítico da relação capitalista, tema que passamos a abordar diretamente.

\title{
O NOVO IMPERIALISMO
}

O novo imperialismo, compêndio das Clarendon Lectures "proferidas na School of Geography and the Enviroment, da Oxford University, nos dias 5, 6 e 7", aparece em fevereiro de 2003, ano em que as discussões sobre a agressão norte-americana ao Iraque, com George Bush filho à frente, ocupava o cenário americano e mundial:

\begin{abstract}
A guerra contra o Iraque, embora aparentemente prestes a eclodir, ainda iria ter início, e permanecia a tênue esperança de que fosse possível impedi-la. [...] Apesar dessa oposição, a ação militar no Iraque foi iniciada sob o comando dos Estados Unidos, com o apoio mais ostensivo da Grã-Bretanha e da Espanha, no dia 20 de março. No momento em que escrevo, o resultado da guerra embora nem um pouco duvidoso do ponto de vista militar, ainda está obscuro. Acabará ela sendo, ou parecendo ser, uma ocupação colonial, um regime clientelista imposto pelos Estados Unidos, ou uma genuína libertação? (Harvey, 2004: 7)
\end{abstract}

Em meio àquela turbulência, o desafio de Harvey seria, numa formulação tipicamente marxiana, fazer emergir "as forças motrizes que agiam por sob o caos das aparências" (Harvey, 2004:8). Devido, talvez, às circunstâncias em que foi escrito, o livro é uma reflexão em grande parte ancorada na história americana. Ainda assim, o texto torna visível o esforço de Harvey em fazer trabalhar seus conceitos e formulações mais gerais para analisar aquela configuração geopolítica que se desenhava no início do século que se abria.

Assim como Giovanni Arrighi, que influenciará a interpretação de Harvey neste trabalho, havia feito a respeito da construção de impérios na Itália, Holanda, Grã-Bretanha e nos Estados Unidos, o geógrafo se concentrará, principalmente, nos dois primeiros capítulos do livro (Harvey, 2004: 11-76), num escrutínio histórico da formação imperial americana, tratando de fazer operar seu materialismo histórico-geográfico e a postulação de um desenvolvimento geográfico desigual na descoberta das origens da ascensão e crise americana, juntamente com suas tentativas de rearranjos a partir de formas renovadas de acumulação.

A dialética interno/externo, que Harvey aproveitara e reconstruíra de Marx, continua sendo ferramenta útil à sua reflexão sobre a política americana recente. Ou seja, é a partir da reconstrução do passado histórico daque- 
le país que Harvey encontrará os mecanismos e os porquês da expansão externa, para daí cogitar sobre o que há de renovado em suas manifestações.

Fato de considerável importância, como anunciado, é a apropriação por parte de Harvey das formulações de Arrighi, principalmente as expostas em O longo século XX. Harvey se baseará na distinção que aquele autor faz entre "lógica política/territorial de poder" e "lógica capitalista de poder". Com o primeiro termo, o autor deseja chamar a atenção para as lógicas mais enraizadas no território e mais dependentes dos desígnios do Estado e da política. Já o segundo, visa pensar a lógica de acumulação atribuindo a ela caráter mais arredio, em alguma medida, "aterritorial". Isto permitirá a Harvey atribuir mais ênfase aos mecanismos de poder centrados no Estado, elemento extremamente subteorizado em seus trabalhos anteriores (Harvey, 2004: 88-93).

Tal distinção é a condição analítica que o permite tematizar uma questão central em seu texto: ou seja, Harvey diferencia, no que é já um passo importante para a definição do que entende como novas formas de acumulação imperialística, a política "neoliberal" da política "neoconservadora" americana. Dizendo esquematicamente, a primeira teria representado um desdobramento, ou na caligrafia harveyana, um rearranjo necessário para dar conta da crise que se instala mundialmente, com desdobramentos desiguais, pós-1973. Isto teria significado um desenvolvimento notável do poder e da influência do capital financeiro, além de uma maré de abertura dos mercados, muito por conta da ajuda de aparelhos internacionais como o Fundo Monetário Internacional (FMI), nomeadamente. Já a segunda, que importa mais a Harvey, pois ela é, digamos, o diagnóstico dos anos por ele investigados, teria sido caracterizada pelo forte intervencionismo estatal, com ênfase no aspecto bélico, lembremos da abertura do livro, acima citada. Quer dizer:

A eleição fortuita de Georg W. Bush, um cristão reconverso, para a presidência dos Estados Unidos deixou um grupo neoconservador de pensadores perto do poder. Os neoconservadores, bem financiados e organizados em inúmeros think-tanks como os neoliberais antes deles, havia muito tentavam impor seu programa político ao governo. E esse programa diferia do neoliberal, tendo por objetivo primordial o estabelecimento da ordem e o respeito a ela, tanto internamente como no cenário mundial. [...] O programa neoconservador de política externa foi formulado no Project for the New American Century, que começou a ser implementado em 1997 (Harvey, 2004:154-155).

Além disso, se no livro anterior Harvey havia feito questão de marcar, talvez de forma excessivamente unilateral, como indicamos, as insuficiências de seus predecessores em tematizar a questão dos rearranjos espaciais, afirmando que Marx não havia contribuído muito neste quesito, é notável em 0 novo imperialismo uma tentativa de retomar a importância do tempo de forma mais explícita para se pensar a dinâmica do capitalismo juntamente à dinâmica espacial. Isto é, em O novo imperialismo se pode ler: "Não é, contudo, possível divorciar essa opção de mudanças temporais em que o capital exce- 
dente é deslocado para projetos de longo prazo que precisam de muitos anos para devolver seu valor à circulação mediante a atividade produtiva que sustentam" (Harvey, 2004: 78).

Assim, podemos notar a crescente preocupação de Harvey em coadunar numa combinação sui generis as ideias de Arrighi, que visam basicamente retomar a importância do território e, consequentemente, do Estado na efetivação dos chamados hegemons, com a retomada de seu tema clássico, o rearranjo espacial, agora combinando-o de forma mais produtiva e menos disjuntiva com as dinâmicas temporais, daí a proposta do termo rearranjos espaço-temporais. Todas estas esferas, por fim, são mobilizadas a partir da retomada do uso de outro conceito, já utilizado em outros trabalhos, a saber, a ideia de coerência estruturada, agora numa acepção geopolítica mais internacionalizada, capaz de articular, num espaço-tempo determinado, para além das puras trocas econômicas, "atitude, valores culturais, crenças e mesmo afiliações religiosas entre os capitalistas e aqueles que são por eles empregados" (Harvey, 2004: 89).

Ocorre que Harvey deseja, igualmente, reconstruir uma teoria do imperialismo para nosso tempo. Para tanto, sumarizará as contribuições de dois dos maiores ícones desta tradição de pensamento. Apesar do diálogo constante com Lênin, que foi responsável por "popularizar" este tipo de discussão, não sem elevar através dela o materialismo histórico a um patamar analítico diferenciado, Harvey identificará nos traços subconsumistas da teoria da polonesa Rosa Luxemburgo um ponto sobre o qual pudesse edificar suas propostas posteriores.

Nosso autor, ao contrário de Luxemburgo, identificará na sobreprodução o ponto nevrálgico do processo de acumulação capitalista. A mola motivadora da expansão de capital para além de suas fronteiras originais não residiria preponderantemente na escassez da demanda vis-à-vis a oferta de capital, o que faria este se rearranjar basicamente em busca de compradores para seus produtos. Este poderia vir a ser um dos problemas, mas não o central. O nuclear para ele é a necessidade constitutiva do capital em manter móvel o processo de acumulação expandida (Harvey, 2004: 116-118).

Tendo reconstruído, a partir das ideias mencionadas, o histórico americano, Harvey levanta a tese de que, dado o momento histórico que se inicia no último quarto de século XX:

Tal como a guerra com relação à diplomacia, a intervenção do capital financeiro com o apoio do poder do Estado equivale com frequência à acumulação por outros meios. Uma diabólica aliança entre os poderes do Estado e os aspectos predatórios do capital financeiro forma as garras de um capitalismo de rapina que tem tanto de práticas canibais e desvalorizações forçadas quanto tem de alcançar o desenvolvimento global harmonioso. Como, porém, devemos interpretar esses outros meios de acumulação? (Harvey, 2004: 114) 
A tese da "acumulação por despossessão" é construída em diálogo constante com a "acumulação primitiva de Marx". Uma vez mais, Harvey avalia como equivocado ou, ao menos, incompleto, o postulado de Marx de acordo com o qual a ideia de acumulação primitiva teria cumprido sua função histórica, restando, na atualidade, obsoleta.

Conforme Harvey, Marx, no Livro I de O capital, trabalha com os pressupostos iniciais "correspondentes em termos amplos ao da economia política clássica": [...] "mercados competitivos de livre funcionamento com arranjos institucionais de propriedade privada, individualismo jurídico, liberdade de contrato e estruturas legais e governamentais apropriadas, garantidas por um Estado facilitador que também garante a integridade da moeda como estoque de valor e meio de circulação", para mostrar em seu término que todo esse ambiente de "paz, propriedade e igualdade" leva à polarização social e à formação, através da centralização e concentração de capital, de monopólios.

Ocorre que tudo isto se passa supondo-se outra condição, o acontecimento histórico da "assim chamada acumulação primitiva". Entretanto:

A desvantagem destes pressupostos é que relegam a acumulação baseada na atividade predatória e fraudulenta e na violência a uma etapa original tida como não mais relevante ou, como no caso de Luxemburgo, como de forma exterior ao capitalismo como sistema fechado. Uma reavaliação geral do papel contínuo e da persistência das práticas predatórias da acumulação primitiva ou original no âmbito da longa geografia histórica da acumulação do capital é, por conseguinte, muito necessária [...] (Harvey, 2004: 120)

Ao invés de encerrá-la (a acumulação primitiva) no tempo, Harvey atribui a ela papel de destaque na atualidade, com a condição de emprestar a ela nova qualidade. Somar-se-iam ao arsenal de componentes da acumulação primitiva, tal como descrita por Marx, mecanismos aprimorados de acumulação (tenha-se em conta, por exemplo, a hipertrofia do capital financeiro desde 1973). Conforme o autor, “a acumulação por espoliação pode ocorrer numa variedade de maneiras, havendo em seu modus operandi muitos elementos fortuitos e casuais". Não obstante, seria possível identificar um procedimento-chave: a liberação de "um conjunto de ativos (incluindo a força de trabalho) a custo muito baixo (e, em alguns casos, zero)", podendo o capital sobreacumulado apossar-se destes ativos e dar-lhes imediatamente um uso lucrativo (Harvey, 2004: 124).

Ao fim e ao cabo, a lógica de Harvey permanece, nuclearmente, similar: a constante reposição da sobreacumulação crônica de capital deve ser escoada por algum canal. No fundo, portanto, manobras como a valorização fraudulenta ou roubo de ações, destruição ou desvalorização de ativos por novas aquisições ou fusões, patenteamento de novas invenções pelas multinacionais farmacêuticas, retirada de direitos dos trabalhadores, desvalorização da for- 
ça de trabalho, privatização de bens como a água, consistiriam em móveis deste imperativo.

Paulo Arantes resume da seguinte forma o raciocínio de Harvey:

Seja como for, a hipótese central de David Harvey para explicar a engrenagem do Novo Imperialismo é preciosa. Nada mais nada menos que reativação de formas supostamente arcaicas de exploração e de dominação, que Harvey está enfeixando sob a denominação única de acumulação por despossessão. Uma fuga para frente, na qual, como se disse, a lógica territorialista de poder volta a ser preponderante, mesmo antagonizando a normalidade aterritorial dos negócios capitalistas correntes, e seu atual paradigma financeiro, no qual se exprime o desejo do capital de não estar fixado em lugar nenhum. Quer dizer: por motivo de uma crise nada trivial, à reprodução ampliada sufocada por essa mesmíssima crise veio em socorro (por assim dizer) um regime de acumulação por "outros meios", na sua grande maioria processos marcados por toda sorte de violência (Arantes, 2004: 46).

Neste estágio não deve ser demais fazer notar um ponto. Conquanto Harvey tente avançar formas mais dinâmicas de entendimento do que chama de desenvolvimento geográfico histórico desigual, escorando sua reflexão nos contornos de rearranjos espaço-temporais dinâmicos, suas análises, em certo sentido, permanecem intrigantemente centradas, ao menos em seus escritos até meados dos anos 2000. Assim, quando Harvey não analisa países do centro europeu, escreve um livro com referência às novas formas de acumulação com foco nos Estados Unidos. Aqui e ali, quando do desenvolvimento de seu arcabouço conceitual mais geral, rascunhados acima, Harvey chama a atenção para as formulações sobre a dependência ou o colonialismo, não os tomando, contudo, enquanto problema de pesquisa (ver Harvey, 2005: 66, 124).

Comentadas acima as ideias de David Harvey - precipuamente apoiadas em raciocínios mais gerais e abstratos, mesmo tendo-se em conta o exemplo dos Estados Unidos, pois vimos que ali o que estava mesmo em jogo era uma tentativa de reconceituação -, cumpre agora apresentar algumas de suas reflexões sobre as cidades, que além de guardarem proveito em si, servem também de oportunidades de enraizamento de suas formulações teóricas.

\section{A CIDADE: ENTRE A ACUMULAÇÃO E A EMANCIPAÇÃo}

Se é verdade que o tema do espaço e sua consubstanciação urbana, a cidade, é recorrente na obra de nosso autor, cumpre, analiticamente, cindi-la enquanto variável heurística de um lado, ou seja, móvel categorial instrumentalizado para fins cognitivo-analíticos e como polis, por assim dizer, de outro, conquanto organicamente, isto é, sócio-historicamente, estas dimensões restem inseparáveis. As abordamos nesta seção na ordem em que logo acima foram caracterizadas. 
Em The right to the city (2008), texto publicado na New Left Review, ao término do segundo parágrafo, Harvey rendia, em forma de citação, a seguinte homenagem a um dos expoentes da assim chamada Escola de Chicago.

Se a cidade é o mundo que o homem criou, é também o mundo onde é consequentemente condenado a viver. Assim, indiretamente, e sem clareza alguma da natureza de sua tarefa, criando a cidade o homem se refez [...] (Park apud Harvey, 2008: 23).

A referência a Robert Park poderia servir de ensejo para a introdução de nosso autor numa longa tradição internamente polissêmica de autores que buscaram pensar o papel das cidades na constituição do que podemos chamar de forma excessivamente genérica de sociabilidades. Interessa-nos no espaço deste texto, entretanto, apresentar o que seria a contribuição de Harvey para a reflexão sobre as cidades, a partir dos dois quesitos supramencionados (heurístico e político), ficando a demonstração de possíveis encontros temáticos e analíticos entre este e os demais pensadores para outra oportunidade. ${ }^{8}$ No quesito que desenvolvemos agora, ou seja, a questão do estatuto heurís tico das cidades, a contribuição de Harvey não foge à sua trajetória reflexiva mais antiga que, como vimos, é fortemente amparada nos escritos de Marx.

Isto significa basicamente que Harvey tenta articular os temas mais gerais, como a acumulação de capital e os rearranjos espaço-temporais daí advindos, com a estruturação das cidades. Apesar de este tema aparecer fortemente em dois de seus livros, The condition of postmodernity (1989) e Paris, capital of modernity (2003), alguns traços deste programa de pesquisa (em sentido lato) já compareciam às páginas de A justiça social e a cidade, precisamente ali onde Harvey discute a formação dos guetos.

Cabe registrar, neste particular, coisa que Harvey faz eventualmente, que o grande insight do geógrafo vem de Engels, particularmente de suas formulações contidas em A situação da classe trabalhadora na Inglaterra e a Questão da habitação (ou moradia), nas quais o alemão assevera que o movimento de acumulação de capital não resolve as crises, e sim as desloca, utilizando-se evidentemente do espaço das cidades para tal.

Pode-se conferir a forma como estas questões se articulam numa análise histórico-concreta, quando Harvey pensa sobre a condição das cidades nos Estados Unidos, notadamente em Baltimore. A discussão sobre a cidade norte-americana é encetada a partir de um tema recorrente à época, ou seja, as discussões sobre o pós-modernismo, que atingia analiticamente o âmbito das cidades na forma de querela entre modelos de planejamento mais monolíticos, racionais, inflexíveis (modernos) ou pós-modernos, supostamente mais criativos, espontâneos e libertadores (Harvey, 2005: 28).

Tendo em vista sua bagagem categorial, o que Harvey faz é evitar a discussão nos termos em que estavam colocados e tentar estabelecer os laços entre a composição das cidades, dentre outros, em seus traçados arquitetô- 
nicos com os movimentos de acumulação, isto é, neste caso, a conexão dos planejadores com os imperativos de mercado que permaneceriam como pujante coordenador das práticas malgrado a proliferação estilística de conteúdo e forma variante.

Além da conexão entre o que Harvey chama de "economia real" e estilo, digamos, evidenciavam-se os vínculos entre aquela e a modulação de experiências subjetivas, notadamente as vivências modificadas de elementos como tempo e espaço, o que Harvey sintetiza sobre o epíteto "compressão tempo-espaço" (space-time compression) (Harvey, 1989: 201-211, 308-327).

No que respeita à sua reflexão sobre as cidades à francesa, à Paris das barricadas de maio de 1968 e das análises de Marx acerca da experiência rica da Comuna e das experiências de 1848-1850, Harvey acrescenta suas anotações sobre os impactos dos traços de um Haussmann sobre os contornos daquela urbe. Em Paris, capital of modernity (2003) perscrutará as consequências dos traçados forjados pelo barão a mando de Luís Bonaparte para a sociabilidade parisiense do segundo império.

Paris, conforme Harvey, passara por um momento de crise significativa. A mesma crise financeira que acometera a Inglaterra, em 1847, antes com suas características básicas de sobreacumulação de capital e força de trabalho chegara a Paris, somando-se às tensões políticas que ali proliferavam (Harvey, 2003: 90).

Sobre este pano de fundo mais geral é que Harvey tenta explicitar os contornos mais determinantes das mudanças. Embora seja para ele discutível a atribuição exclusiva das mudanças arquitetônicas a Haussmann (que assume a liderança do projeto em 1853 até 1870, quando é dispensado por Émile Olivier, primeiro ministro liberal), tendo em vista que elas já vinham sendo implementadas por seus antecessores como Berger (Harvey, 2003: 8-9), a paisagem parisiense "antiga" é sintetizada por Harvey da seguinte forma:

\footnotetext{
Enquanto não havia nada de único com relação à miséria humana, degradação, doenças, crimes, e prostituição - características bastante comuns ao capitalismo industrial de então - essa infraestrutura urbana antiga era incompatível com a organização capitalística da produção crescentemente sofisticada e eficiente, assim como o consumo emergindo nas novas cidades manufatureiras não somente na Inglaterra o principal rival comercial da França - mas também na Bélgica, Alemanha, Áustria e mesmo outras regiões na França (Harvey, 2003: 92)
}

Neste quadro, Haussmann serviria bem aos imperativos de renovação da cidade. A fortuna do momento somada à sua virtú arquitetônica pautada no apreço pelas linhas retas, escalas exageradamente alargadas etc., rearranjariam Paris na medida certa, para moldá-la às necessidades (em sentido forte) da ocasião.

Como forma de comparar representações sobre as cidades são apresentados os relatos de Honoré de Balzac, Gustave Flaubert e Charles Baude- 
laire. Atribuindo importância à sua própria démarche, o geógrafo prefere as representações citadinas de um Carl Schorske, pois capaz de reproduzir em seus relatos "um senso de totalidade a respeito da cidade", virtude que Harvey, por outro lado, não reputa a Benjamin, excessivamente fragmentário (Harvey, 2003: 18).

Conquanto seja discutível a atribuição de unilateralidade a Benjamin, o fato é que Harvey tenta alcançar um entendimento próprio da cidade, como frisamos ao longo da seção, a partir de suas elaborações mais gerais. À disputa de representações com relação às cidades é somada a explicitação, por Harvey, da cidade enquanto espaço político (em termo lato, polis).

Esta visão nos leva novamente a Park, mas, em The rebel cities (2012), a partir de uma angulação diferente. Harvey se interroga acerca das formas sociais e políticas construídas pelos homens quando se "refazem" ao "fazer" a cidade, remetendo-o à preocupação acerca da organização e da luta coletiva nesta construção, os quais, obviamente, terão impacto nos processos de urbanização.

Se Park está correto, então a questão do tipo de cidade que nós queremos, não pode ser divorciada da questão do tipo de pessoas que queremos ser, do tipo de relações sociais que buscamos, da relação com a natureza que queremos nutrir, do tipo de estilo de vida que desejamos, bem como dos nossos valores estéticos. [...] Reinventar a cidade, inevitavelmente, depende do exercício de um poder coletivo sobre os processos de urbanização (Harvey, 2012: 4).

"Fazer", "refazer", "reinventar". Termos cheios de significados, que nos remetem ao universo da ação como seu elemento mais proeminente. Mas, como isso se daria se Harvey vincula os processos de urbanização com a acumulação capitalista? Ele mesmo assevera que a urbanização "tem sido, através de toda a história do capitalismo, um elemento-chave para a absorção de capital e trabalho excedentes" (Harvey, 2012: 42). Desta forma, mais do que pensar nas formas como o "homem" se "refez", Harvey assinala a necessidade de se pensar as formas pelas quais nos fomos moldados pelos processos de urbanização impulsionados por forças sociais poderosas.

Isso poderia, em certa mirada, deixar espaço exíguo para ações alternativas. Harvey parte exatamente disso para ver, aí mesmo, tendo em vista as contradições produzidas pelo referido vínculo, um eito fértil.

A reprodução do capital passa pelos processos de urbanização via uma miríade de formas. Mas a urbanização do capital pressupõe a capacidade dos poderes da classe capitalista de dominar o processo urbano. Isto implica que a dominação da classe capitalista não é apenas sobre os aparatos do Estado (em particular aqueles aspectos do poder de Estado de administração e governo das condições sociais e de infraestrutura dentro das estruturas territoriais), mas, também, sobre o conjunto da população - seus estilos de vida, assim como sua força de trabalho, seus valores políticos e culturais, suas concepções mentais do mundo. Este nível de controle não ocorre facilmente. A cidade e o processo urbano que a produz tornam-se daí em diante locais centrais de luta política, social e de classe (Harvey, 2012: 66). 
Ao apontar a cidade como este locus central, e ainda mais, um espaço de luta, Harvey abre possibilidades alternativas para o seu destino, trabalhando o que seria uma lacuna nas formulações marxianas, que ou as teriam ignorado ou considerado esvaziadas em termos de potencial revolucionário. ${ }^{9}$

Na visão de Harvey (2012: 65), se a forma de urbanização capitalista "está tão completamente imbricada na reprodução capitalista, lhe sendo mesmo fundacional, então as formas alternativas de urbanização devem, necessariamente se tornar centrais para qualquer busca de uma alternativa anticapitalista".

Como o processo de urbanização capitalista situa-se no bojo do processo de reprodução do sistema, as lutas urbanas deveriam se direcionar, em termos de seus conteúdos, para produzir inflexão e mudança neste processo. Assim, deveria ser um ponto de convergência destas lutas a busca do controle tanto do uso do excedente, como também de sua produção. Não se trataria apenas de colocar mais e mais excedente sob controle do Estado. Isto só funcionaria com a condição de uma radical democratização do Estado sob controle popular.

A partir deste tipo de visão, Harvey assinala a necessidade de não se tomar a ideia do direito à cidade como um slogan vazio. Ela não seria um fim, mas um meio. Em sua apropriação crítica das formulações de Lefebvre, Harvey (2012: xv) aponta para o fato de que "o direito à cidade seria vazio de significado, dependendo sempre de quem o preencheria de sentido. Como disse Marx em O Capital 'entre direitos iguais, a força decide. A definição de um direito já é objeto de luta. Esta luta prossegue concomitantemente a luta por materializá-lo'”.

O ponto de convergência na luta por este direito pode associar muitos grupos e movimentos presentes no urbano, mas a eficácia e impacto deles vai depender, como tarefa política, de uma visão mais ampla em termos de projeto, bem como de uma abrangência e forma de organização diferente, bastante além do imaginado por Lefebvre.

A cidade tradicional tem sido morta pelo voraz desenvolvimento capitalista, vítima da infinita necessidade de desaguar capital superacumulado em direção ao crescimento e à expansão urbana sem fim, não se importando com suas consequências sociais, ambientais e políticas. A tarefa política seria, segundo Lefebvre, construir uma cidade totalmente nova. Mas isso só será possível com a criação de um vigoroso movimento anticapitalista que tenha como meta a transformação da vida urbana cotidiana (Harvey, 2012: xv). 


\section{À GUISA DE CONCLUSÃO: A TEORIA CRÍTICA DE DAVID HARVEY}

Há, naturalmente, diversas e variadas possibilidades de modulação no que concerne à ideia de crítica: imanente, transcendente, negativa, positiva, redentora etc., cada qual sendo responsável por estabelecer, a seu modo, vínculo crítico com seu objeto de reflexão. Não teríamos espaço, aqui, para elencar substantivamente, isto é, do ponto de vista dos problemas e questões, as distintas tradições. ${ }^{10}$

Pode-se dizer, contudo, que distintamente de uma crítica no sentido kantiano do termo, isto é, do procedimento transcendental de burilar categorias, claras e distintas, relativas às condições de possibilidade do conhecimento, Harvey ampara-se no sentido marxista de crítica, que se caracteriza por ao menos dois aspectos: de um lado, a perscrutação das determinações mais estruturais que condicionam a constituição das ações e representações. De outro, pela transformação da crítica da representação em crítica prático-social.

De fato, Harvey desenvolve sua reflexão mantendo a liberdade e a dominação, polos naturalmente normativos, como valores-chave de seu arcabouço conceitual. Em procedendo desta forma, e elegendo, naturalmente, o polo da liberdade como espécie de princípio analítico regulador, assume uma demanda central do projeto moderno, apoiando sua crítica na cobrança das "promessas" sociais, normativas e institucionais não cumpridas por aquele, procedimento que lhe renderia o status de crítico imanente (Benhabib, 1986).

Entretanto, diferentemente de outros autores postados dentro deste mesmo modelo de crítica - Max Weber vem logo à mente, mas poderíamos pensar em Habermas também -, o autor combina a explicitação de forma incisiva à incapacidade crônica do capitalismo de ofertar plenamente as promessas de seus processos fundadores, postulando a necessidade da construção política de novos mundos, ou seja, sua transcendência, o que lhe aproxima das características mais patentes de um teórico crítico.

Como seria fácil demonstrar ainda em relação aos dois alemães supramencionados, esta proposição política transcendente de Harvey é apoiada certamente em convicções políticas, mas, acima de tudo e com força notável seu posicionamento no mundo é fruto radicalmente lógico de sua empostação teórica.

De fato, como vimos acima, isto resulta de seu interesse e investimento na obra de Marx, fortemente marcada por sua trajetória intelectual ligada à geografia, o que empresta novidade ao seu raciocínio e conjura posições dóxicas quanto ao pensamento do alemão. O ponto decisivo, contudo, é que a leitura de Harvey dos textos de Marx é baseada em seus pressupostos fundadores: teoria do valor trabalho (mais-valia), lei geral de acumulação, "teo- 
ria" das crises etc. Ao segui-los, com uma radicalidade lógica notável, Harvey acaba por ter que postular teórica e praticamente a necessidade de uma transformação revolucionária da sociedade como condição para a expressão de valores como a liberdade, sem a qual a utopia restaria mesmo um não-lugar.

A propósito, isto é, no que respeita à qualidade da relação entre teoria e prática, Goran Therborn, recentemente - na verdade retomando um argumento também já reapropriado por Perry Anderson sobre as características do marxismo ocidental -, ao verter a metáfora leninista das três fontes do marxismo numa figura geométrica em Depois da dialética: teoria social radical em um mundo pós-comunista (2007), nos instou a pensar o marxismo como um triângulo cujos lados seriam: a filosofia, a ciência social e a política. Conforme o teórico social sueco, a figura restaria quebrada, resultado do desencontro entre seus lados, que ficaria patente na dificuldade de conciliar, numa era pós-experiências "socialistas", as dimensões teóricas ("filosofia" e "ciência social") com a política.

Eis aí o segundo quesito da crítica em sentido marxista. Com relação a ele, em textos recentes, Harvey tem buscado pensar os rumos dos movimentos de contestação pelo mundo, sem descurar do papel dos intelectuais neste debate, retomando a reflexão em seu lado mais prático, a partir, para mencionar uma terceira acepção possível da crítica, das autocríticas relacionadas aos movimentos progressistas das últimas décadas.

No que tange à relação com as forças sociais atuantes na sociedade, sua relação com os movimentos não se dá nem no sentido de buscar obrigá-los às suas formulações, nem de se obrigar aos desígnios dos mesmos. Ele compreende esta relação muito mais como uma via de mão dupla, no sentido de um diálogo, de trocas, sem prejuízo da manutenção de autonomias.

Este tipo de relação abriu a Harvey a possibilidade de, a um só tempo, perceber limites e possibilidades nestes movimentos. Algumas de suas ponderações sobre os movimentos sociais atuais servem para pensarmos um aspecto importante de sua teoria crítica, que se relaciona particularmente com sua visão sobre as formas organizativas contemporâneas.

Um ponto recorrentemente sinalizado por Harvey em diversos textos e oportunidades tem sido sua preocupação com o problema das "escalas". Ele reforça a ideia da limitação de algumas visões organizativas presentes no interior dos movimentos que varreram e varrem o cenário global, principalmente, nos relacionados ao urbano.

No seu entendimento, muitos destes importantes movimentos padecem de uma limitação trazida por sua crítica radical às formas de organização vertical. Nestes termos, segundo ele, deixam de perceber que a organização horizontal que tomam como princípio inquebrantável, se funciona em determinada escala, pode não funcionar em uma escala maior, quando se lida com 
a necessidade de articulações em outros níveis. Na mesma direção, se pode pensar que as possibilidades de organização verticais não necessariamente são indispensáveis ou obrigatórias em uma escala reduzida.

Para Harvey, sem temer a ideia de hierarquia, deve-se entender que se pode articular formas de organização horizontais e verticais. ${ }^{11}$ A dificuldade de desenvolver esta percepção pode ter impactos pesados sobre estes movimentos, como a sentida falta de estrutura vertical que, em sua ausência, teria levado alguns destes movimentos à exaustão organizativa, à falta de impactos maiores e ao desaparecimento, como ocorreu, nomeadamente, com o Occupy.

Quanto ao quesito mais programático, Harvey defende a necessidade de uma articulação não só entre movimentos, mas a orientação destes para uma transformação radical das bases da sociedade. Assim, se não se pode falar de luta socialista sem inseri-la nas lutas da cidade, não se pode também falar de lutas da cidade, se elas querem efetivamente alterar o que tem produzido os problemas pelos quais se batem, sem inseri-las em uma luta socialista de maior escopo. Articularia-se um processo que vai do direito à cidade à revolução urbana. ${ }^{12}$

Contudo, longe de uma postura ingênua e voluntarista, Harvey percebe que "como estes grupos tão diferentes se auto-organizarão em uma força revolucionária é um grande problema político" (Harvey, 2012: xiv). Contudo, avançando elementos nesta direção, nos lembra que "parte da tarefa é entender as origens e a natureza de seus apelos e demandas".

Como forma de conclusão, podemos dizer que a elaboração crítica de Harvey condensa numa espécie de síntese (provisória) alguns elementos que têm percorrido toda a sua reflexão ao longo do tempo, e que podem representar um ponto de partida instigante para novas formulações investigativas.

Em suma, pode-se perceber a existência de uma linha mestra de pensamento munida de um núcleo central abstrato - apoiado em Marx e na tradição marxista -, que discute, fortalecendo-se, com objetos concretos do conhecimento. Pela própria formação de Harvey, estes objetos tenderam a se relacionar com as preocupações do campo geográfico. Sua teoria dos rearranjos espaço-temporais auxiliou na renovação das interpretações sobre o capitalismo mais contemporâneo. Isto fica claro, por exemplo, nas suas tentativas de tornar inteligíveis as novas formas de configuração societais, principalmente nos últimos quarenta anos, marcados por ao menos dois traços mais salientes: um rearranjo considerável dos países em nível internacional, isto é, a configuração de uma nova divisão internacional do trabalho e uma majoração significativa do papel do capital financeiro. A partir das cidades, o autor estabelece vínculos fortes entre capitalismo e urbanização, levando à produção de contradições que terão a cidade como locus político de luta. De lutas e de movimentos de contestação que precisam não só ter claro seus 
objetivos, como formas de organização adequadas, na busca da superação das condições nas quais se batem. Assumindo a normatividade como constitutiva de qualquer formulação reflexiva, Harvey leva adiante as tarefas de um teórico social crítico, renovando-as. Atividade que ele defende com convicção e em prática devotada.

Recebido em 06/02/13|Aprovado em 04/05/13

Marco Aurélio Santana é professor do Departamento de Sociologia e do Programa de Pós-Graduação em Sociologia e Antropologia (PPGSA/UFRJ), da Universidade Federal do Rio de Janeiro, onde também coordena o Núcleo de Estudos Trabalho e Sociedade (NETS-UFRJ).

Igor Peres é mestrando em Sociologia pelo Instituto de Estudos Sociais e Políticos da Universidade do Estado do Rio de Janeiro (IESP/UERJ), onde participa do Núcleo de Pesquisas Sociofilo, e bolsista do Conselho Nacional de Desenvolvimento Científico e Tecnológico (CNPq). 


\section{NOTAS}

1 Qualquer levantamento histórico a respeito do desenvolvimento do marxismo ao redor do globo, e nos Estados Unidos em particular, atesta isso. Por ora, como demons tração possível, pode-se indicar o volume de sua obra na última década e o debate gerado por ela, o qual aglutinou intelectuais de renome não só pertencentes ao campo do marxismo, mas também estranhos a ele.

2 Mesmo que a apropriação de Harvey com relação a estes escritores seja diversa e multidimensional, vale ressaltar algumas obras de referência para cada autor mencionado: Popper, Karl, A lógica da pesquisa científica; Lefebvre, Henry, A produção do espaço; Marx, Karl, O capital; Engels, Friedrich, A situação da classe trabalhadora na Inglaterra; Luxemburgo, Rosa, A acumulação do capital e Arrighi, Giovanni, O longo século $\mathrm{XX}$.

3 Harvey resume da seguinte esta posição: "[...] Geralmente, o conhecimento geográfico era extremamente frag mentado, dando grande ênfase ao que se chamava de 'excepcionalismo'. A doutrina estabelecida afirmava que o conhecimento produzido por cada investigação geográfica era diferente um do outro. Não podia ser generalizado, não podia ser sistematizado. Não havia leis geográficas; não havia princípios gerais para os quais apelar - tudo o que você podia fazer era partir, por exemplo, para a região seca do Sri Lanka, e passar a vida estudando e entendendo aquilo" (Harvey, 2005: 18).

4 Crítica à ortodoxia geo-lógica que não se limitou exclusivamente aos egressos do campo, mas que aproximou também do debate nomes importantes da teoria social. Só para ficarmos em um exemplo, lembremos das páginas provocativas escritas por Pierre Bourdieu em "A identidade e a representação. Elementos para uma reflexão crítica sobre a ideia de região", recolhido no Brasil em O poder simbólico (2007), em que o autor apresenta uma crítica histórico-relacional de uma das ideias-chave do métier geográfico, isto é, a ideia de região.

5 Seguiremos, ao longo deste texto, a tradução feita por Danilo Cerqueira Cesar do artigo de Harvey intitulado "O 'novo' imperialismo: sobre rearranjos espaciotemporais e 
acumulação mediante despossessão", publicado na Revista Margem Esquerda - Ensaios Marxistas, $n^{\circ}$ 5, 2004. Nas traduções anteriores como, por exemplo, a tradução de $A$ produção capitalista do espaço (2005), o termo vem reproduzido como "reajuste". Ratificamos a justificativa do tradutor que visava basicamente manter a acepção processual da palavra, tendo em vista sua inserção no conjunto de reflexões de Harvey que buscam justamente explicitar em novas modalidades e novos contextos a característica extremamente dinâmica do modo de produção capitalista. O mesmo vale para o termo "dispossession", vertido aqui para "despossessão", alternativamente a espoliação, como vem na tradução de 0 novo imperialismo (2004).

6 Marx teria insistido, por exemplo, na importância da "anulação do espaço pelo tempo" através de investimentos em elementos como transporte e comunicação, isto é, da utilização pelo capital de inovações de sorte variada para encurtar o tempo necessário de rotação do capital para que o valor produzido seja realizado e retorne às mãos dos capitalistas (Harvey, 2005: 49). Nesta chave, o espaço, para Harvey, seria pensado exclusivamente como estorvo a ser ultrapassado, desenhando-se uma definição por demais negativa, sem mais preocupações acerca de qual é realmente o papel do espaço.

7 Harvey refere-se ao capítulo XXXIII do Livro I de O capital (1990: 931-940) da tradução para o inglês utilizada por Harvey, por exemplo, em seus cursos recentes sobre 0 capital (ver Harvey, 2010)

8 A título de exemplo caberia mencionar de passagem os seguintes autores situados no campo da teoria social ou da sociologia propriamente dita: Weber (1994), Simmel (1973) e Benjamin (1996).

9 Katznelson (1992) analisa as iniciativas marxistas de estudos sobre a cidade. Em uma de suas partes, o autor, dedicando-se ao marxismo dos anos 1960 e 1970, coteja as obras de Harvey, Lebfevre e Castells. Deve-se dizer, no caso deste último, que o seu livro A questão urbana, de 1972 (edição brasileira de 1983), marcado pela perspectiva althusseriana, é um esforço reconhecido que o situa entre os pioneiros. 
10 Só como breve ilustração, apontaríamos: a crítica da alienação (Hegel), a crítica do capitalismo (Marx), a crítica da razão instrumental (Adorno e Horkheimer), a crítica democrática, intersubjetiva e dialógica da filosofia do sujeito (Habermas) etc.

11 Segundo Harvey, "Infelizmente, como já notado, a ideia de hierarquia é, nos dias que correm, um anátema para muitos dos segmentos da oposição de esquerda. Um fetichismo da preferência organizacional (pura horizontalidade, por exemplo) frequentemente obsta o caminho de exploração de soluções efetivas e apropriadas. Para ser claro, eu não estou dizendo que a horizontalidade é ruim. De fato eu a considero um excelente objetivo. Mas, devemos reconhecer que ela tem limites como um princípio organizacional, bem como estarmos preparados para ir além dela quando for necessário" (Harvey, 2012: 70).

12 Na visão de nosso autor, "Só um movimento revolucionário mais amplo poderia erradicar as práticas dominantes de produção do espaço. Todo o sistema capitalista de perpétua acumulação junto com suas estruturas associadas de exploração de classe e poder de Estado têm de ser destronadas e substituídas. Clamar pelo direito à cidade é apenas uma estação de parada na estrada até esta meta. Isto não pode ser um fim em si mesmo, ainda que se apresente como o mais propício caminho a seguir" (Harvey, 2012: xvi). 


\section{REFERÊNCIAS BIBLIOGRÁFICAS}

Arantes, Paulo. (2004). Último round. Revista Margem Esquerda, 5, p. 41-51.

Arrighi, Giovanni. (2009). O longo século XX. São Paulo: Contraponto.

Barnes, Trevor. (2006). Between deduction and dialectics: David Harvey on knowledge. In: Castree, Noel \& Gregory, Derek (orgs.). David Harvey, a critical reader. Oxford: Wiley-Blackwell (Antipode Book Series), p. 26-47.

Benhabib, Seyla. (1986). Critique, norm and utopia: a study of the foundations of Critical Theory. Nova York: Columbia University Press.

Benjamin, Walter. (1996). Obras escolhidas. São Paulo: Brasiliense (vol. I).

Callinicos, Alex. (2006). David Harvey and Marxism. In: Castree, Noel \& Gregory, Derek (orgs.). David Harvey, a critical reader. Oxford: Wiley-Blackwell (Antipode Book Series), p. 47-55.

Castells, Manuel. (1983). A questão urbana. Rio de Janeiro: Paz e Terra.

Domingues, José Maurício. (2011). Vicissitudes e possibilidades da teoria crítica hoje. Sociologia \& Antropologia, 1/1, p. 71-89.

Domingues, José Maurício. (2003). A cidade: racionalização e liberdade em Max Weber. In: Do Ocidente à Modernidade: intelectuais e mudança social. São Paulo: Civilização Brasileira, p. 79-112.

Gregory, Derek. (2006). Introduction: troubling geographies. In: Castree, Noel \& Gregory, Derek (orgs.). David Harvey, a critical reader. Oxford: Wiley-Blackwell (Antipode Book Series), p. 1-26.

Harvey, David. (2012). Rebel cities. Londres: Verso.

Harvey, David. (2010). A companion to Marx's Capital. Londres: Verso.

Harvey, David. (2008). The right to the city. New Left Review, 53, set./out., p. 23-40.

Harvey, David. (2005). A produção capitalista do espaço. São Paulo: Annablume. 
Harvey, David. (2004). O novo imperialismo. São Paulo: Loyola.

Harvey, David. (2004). O "novo" imperialismo: sobre rearranjos espaciotemporais e acumulação mediante despossessão. Revista Margem Esquerda, 5, p. 31-41.

Harvey, David. (2003). Paris, capital of modernity. Nova York/ Londres: Routledge.

Harvey, David. (1989). The condition of postmodernity. Nova York: Blackwell Publishres.

Harvey, David. (1980). A justiça social e a cidade. São Paulo: Global.

Harvey, David. (1969). Explanation in geography. Londres: Edward Arnold and St Martin's Press.

Jessop, Bob. (2006). Spatial fixes, temporal fixes and spatio-temporal fixes. In: Castree, Noel \& Gregory, Derek (orgs.). David Harvey, a critical reader. Oxford: Wiley-Blackwell (Antipode Book Series), p. 142-167.

Katznelson, Ira. (1992). Marxism and the city. Oxford: Clarendon Press.

Lojkine, Jean. (1981). O estado capitalista e a questão urbana. São Paulo: Martins Fontes.

Simmel, Georg. (1973). A metrópole e a vida mental. In: Velho, Otávio (org.). O fenômeno urbano. São Paulo: Zahar, p. 11-25.

Therborn, Göran. (2007). Depois da dialética: teoria social radical em um mundo pós-comunista. Revista Margem Esquerda, 10, p. 109-128.

Weber, Max. (1984). Economía y sociedad. Esbozo de sociología comprensiva. México: Fondo de Cultura Económica. 
Palavras-chave

Acumulação capitalista; Espaço; Cidade; Política;

Teoria social.

Keywords

Capitalist accumulation;

Space; City; Politics;

Social theory

\section{CAPITALISMO, CIDADE E POLÍTICA NA PERSPECTIVA} DE DAVID HARVEY

\section{Resumo}

O texto discute alguns eixos conceituais relevantes para a compreensão da obra de David Harvey, concentrando-se especificamente nas formulações do autor acerca da ideia de rearranjo espacial (spatial fix), de novo imperialismo (new imperialism) e de acumulação mediante despossessão (acumulation by dispossession). Objetiva-se lidar também com o que se seriam os componentes da teoria crítica de Harvey. Além disso, apresenta-se como tais ideias e formulações não podem ser plenamente entendidas sem 0 seu enraizamento nas reflexões do autor acerca das cidades.

\section{CAPITALISM, CITY AND POLITICS IN DAVID HARVEY'S PERSPECTIVE}

\section{Abstract}

This article discusses some significant concepts for the understanding of David Harvey's works. It focuses on three specific theoretical constructions based on the ideas of spatial fix, new imperialism and accumulation by dispossession. It also addresses what might be called Harvey's critical theory. It is argued that to understand Harvey's ideas properly it is necessary to situate them within his studies on cities. 